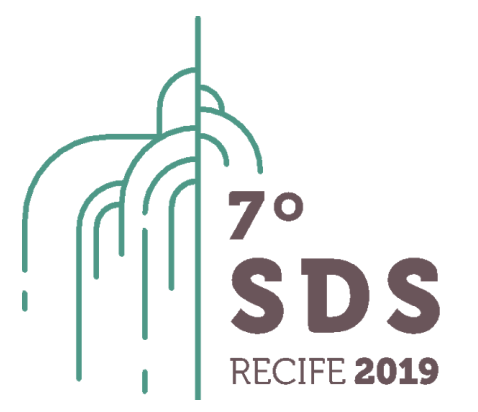

$-$

SIMPÓSIO

DESIGN

SUSTENTÁVEL
SUSTAINABLE

DESIGN

SYMPOSIUM

\title{
Biocompósito de resíduo de jupati aplicado a produtos artesanais
}

\author{
Amanda Paloma Bahia dos Santos (Bacharel) ${ }^{1}$, Ninon Rose Tavares Jardim (Mestre) ${ }^{2}$ \\ ${ }^{1}$ Universidade do Estado do Pará, Design, amanda.pba.santos@gmail.com \\ ${ }^{2}$ Universidade do Estado do Pará, Design, ninonjardim@gmail.com
}

Resumo. A pesquisa tem como intuito elaborar um biocompósito utilizando o descarte da produção artesanal com o pecíolo do jupati da comunidade do furo Pirarara, em São Sebastião da Boa Vista no arquipélago do Marajó, e ensinar esta tecnologia aos artesãos para ser aplicado em novos produtos, dessa forma possibilitando mais uma fonte de renda à comunidade e originando um destino ao resíduo descartado, utilizando a matéria-prima local sem qualquer desperdício. Portanto, os princípios do ecodesign e do desenvolvimento sustentável foram aplicados, assim como o design e território. Na etapa final, realizou-se um workshop para ensinar os artesãos a tecnologia social desenvolvida, ocasião em que eles puderam conhecer o jupati de uma forma não habitual, resultando em três linhas de produtos retiradas do cotidiano da comunidade.

Palavras-chave. Sustentabilidade; Pecíolo; Jupati; Compósito; Artesanato.

\section{Introdução}

O presente estudo tem como propósito reaproveitar os resíduos do jupati (Raphia taedigera) no desenvolvimento de um compósito para ser aplicado em produtos artesanais na comunidade de São Sebastião da Boa Vista, arquipélago do Marajó- PA. Essa pesquisa nasceu pela observação do descarte considerável de um resíduo regional, "bucha" do jupati, gerado na produção artesanal de Boa Vista e a falta de pesquisas do seu reaproveitamento também no artesanato. O tema se propõe a unir as questões sustentáveis, com foco no material, com a elaboração de produtos que valorizem uma identidade local, presente principalmente no artesanato.

No âmbito de Design, elaborar produtos e serviços com o viés da sustentabilidade deve estar intrínseco ao projeto e uma maneira de alcançar este objetivo é por meio da utilização de materiais alternativos. Um segmento que evidencia, além de uma identidade cultural, a harmonia com a natureza é o artesanato. Muitas comunidades se apropriam apenas daquilo que servirá para gerar seu sustento, deixando nítido o respeito ao tempo que a natureza necessita para oferecer a 
matéria-prima de seu trabalho. Mas, apesar de ser evidente esse respeito com a natureza, nem sempre a matéria-prima é utilizada por completo na produção e então resíduos são gerados, em sua maioria biodegradáveis, já que são naturais, e que poderiam ser inseridos em outros processos.

É o caso dos artesãos de São Sebastião da Boa Vista que residem no furo Pirarara, famosos pelos trançados feitos a partir da fibra do jupati, retirada do pecíolo do jupatizeiro de onde tala e fibras são utilizadas na confeç̧ão de artigos decorativos, acessórios de moda e cestaria. Porém a "bucha" (parte entre o centro e as extremidades do pecíolo) é descartada pelos artesãos. 0 objetivo da pesquisa é elaborar um compósito utilizando este descarte da produção artesanal e ensinar a comunidade a desenvolvê-lo a fim de que esse processo possa ser utilizado no desenvolvimento de novos produtos, visando diversificar a produção artesanal e envolver os jovens que estão se afastando desse saber-fazer, possibilitando, portanto, uma nova fonte de renda à comunidade.

O projeto é relevante tanto na questão social, incentivando outra possibilidade de renda à comunidade, quanto para engrandecer a produção científica da região amazônica. O Design, juntamente ao ato de solucionar problemas, tem um papel social de extrema importância, que transcende a materialização de produtos ou serviços, tem o poder de melhorar significativamente a vida do usuário e/ou de uma comunidade, já que a função do designer é projetar para o outro. Juntar este fator ao projetar de forma sustentável foi um desafio que com dedicação se tornou possível.

\section{Referencial teórico}

A pesquisa gira em torno do reaproveitamento do material visando sua aplicação em produtos artesanais, sendo assim, entender alguns conceitos que concernem a pesquisa torna-se primordial. Para tanto, dialoga-se com Manzini e Vezzoli (2016), que traz em sua bibliografia conceitos de sustentabilidade e ecodesign; com Krucken (2009) para compreender mais sobre o design e território e a valorização de recursos e produtos locais; com Borges (2011) sobre a importância do artesanato e de que forma o design(er) auxilia no projeto de produtos artesanais; bem como os aportes de Jardim (2013) e Costa e Simões (2011) para entender de que forma é realizado e propagado esse saber-fazer artesanal em São Sebastião da Boa Vista.

Autores como Lima (2006), Ashby (2011), Santos, N. (2010) e Oliveira et al (2003) juntam-se a esse quadro para elucidar os materiais e processos produtivos mais utilizados pela indústria, as características das fibras naturais e do principal material da pesquisa, o jupati. Esses, juntamente a outros autores, fundamentaram e guiaram a pesquisa para que alcançasse um resultado satisfatório. Com os conceitos já estabelecidos, o projeto parte para a etapa de elaboração e teste com o material criado e sua aplicação na comunidade em questão.

\subsection{Material e processo produtivo}

A participação do Design se destaca principalmente na elaboração do compósito, dessa forma, no que tange a produção, é importante ressaltar os materiais e processo produtivo utilizado no seu desenvolvimento.

\subsection{O Jupati}

O jupati (Raphia taedigera) da família Arecaceae, é uma palmeira amazônica que cresce em área de várzea e tem porte mediano (OLIVEIRA, J. et al, 2003, p.1).

Oliveira et al (2003) descreve que a região da planta de onde provém a tala (parte externa) e fibras (parte interna) é o pecíolo, matéria-prima utilizada para fazer matapis ${ }^{1}$, cestas, armações, objetos de moda e decorativos.

\footnotetext{
${ }^{1}$ Instrumento utilizado na pesca artesanal do camarão.
} 
O pecíolo (fig. 1 folha pinada) é a estrutura que prende o limbo da folha ao estipe (caule da palmeira), inserido de forma direta ou por intermédio de uma dilatação, a bainha (FERRI, 1983). Desta parte, popularmente conhecida como "vara", é extraída a fibra longa, leve, grossa, branca e de brilho natural marcante (JARDIM, 2013, p. 13).

Figura 1- Estruturas das folhas pinadas e palmadas de uma palmeira, respectivamente, jupati se apresenta como folha pinada

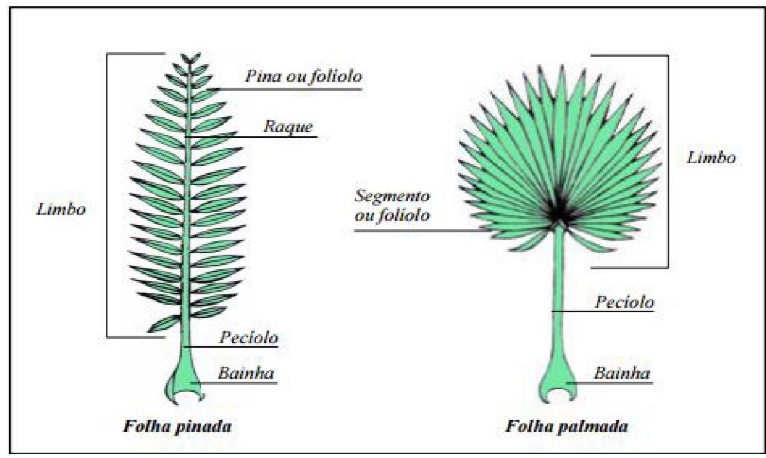

Fonte: SODRÉ, 2005, p. 14

No processo de obtenção da matéria-prima, algo importante a ser levado em consideração é o saber empírico do melhor período para colheita das varas do jupati e a extração de sua fibra, já que esse ato está ligado diretamente à resistência do material. Nesse sentido, Jardim (2013), descreve que é um processo que parte da observação e da relação com a mata e a influência que a lua tem sobre ela, "[...] segundo os relatos das mulheres, o jupati tirado em noite com lua não presta, pois arrebenta com facilidade, fica manchado e tem pouca durabilidade [...]" (Ibid., p. 129-130). Isso acontece "porque em noite de luar há ocorrência de ponilhas, um tipo de traça que fura o jupati" (COSTA; SIMÕES 2011, p. 84).

O artesão é o principal detentor dessas informações, pois somente quem está imerso no cenário e diretamente relacionado com a matéria-prima conhece tais peculiaridades. Aqui, evidencia-se que o saber científico e empírico quando trabalhado em conjunto atingem resultados mais satisfatórios e completos.

\subsection{Biocompósitos}

Os compósitos são aqueles formados por duas ou mais fases, chamadas de matriz (geralmente sendo um polímero) e reforço (carga sintética ou natural), com propriedades mecânicas diferentes a se complementarem, (TITA et al, 2002 apud SANTOS, N., 2010, p. 19). Entretanto, existem os biocompósitos, caracterizados pelo baixo impacto ambiental já que em sua formação utilizam componentes naturais (biopolímeros, biomassas, fibras naturais e resíduos).

\section{4 papel}

O papel é formado "por fibras celulósicas que se entrelaçam umas com as outras, garantindo a sua resistência. A principal matéria-prima para a obtenção industrial dessas fibras é a madeira, proveniente do tronco das árvores" (SANTOS, C., et al, 2001, p. 4), principalmente as de eucalipto e pinus.

É um material que passa por um longo processo químico para que seja formado e acarreta alguns danos ao meio ambiente além de que apresenta um tempo de vida útil muito curto, sendo descartado logo após sua utilização. A reciclagem vem como solução para amenizar tais problemas, "já que existe a possibilidade de o papel retornar em sua totalidade como matéria-prima para o processo fabril de um novo" (PAMPLONA, 2012, p.19).

O papel então é entendido como a matriz do compósito e o resíduo do jupati como o 
reforço, todavia para que essa união seja firmada é necessário um terceiro elemento, a cola (aditivo aglutinante do compósito).

\section{Experimentação}

Após a investigação do problema e todo o arcabouço teórico realizado, tem-se como foco elaborar e experimentar o compósito, analisar as amostras e definir os prováveis segmentos de produtos. Feito isso, sua verificação culmina em um workshop promovido na comunidade às margens do rio Pirarara, no município de São Sebastião da Boa Vista com a participação dos artesãos.

\subsection{Primeiro contato}

Realizou-se a primeira experimentação a fim de analisar como o material se comporta em diferentes situações. Para isso, todo o processo foi pensado de modo que os artesãos pudessem executá-lo sem grandes entraves em Boa Vista.

Foram elaborados quatro testes utilizando o jupati, jornal, papel pós-consumo, anilina, cola branca e cola de madeira, dois testes com moldes feitos de isopor e dois modelados à mão. A princípio os resíduos de jupati foram cortados em pedaços de aproximadamente $2 \mathrm{~cm}$ colocados em uma bacia com água por 48 horas em temperatura ambiente. Um dia depois foi realizado o mesmo processo com papel pós-consumo (apostilas de papel sulfite) e jornal, cortados em pedaços pequenos e colocados em bacia com água em temperatura ambiente por 24 horas.

Figura 2- Materiais em bacia com água, resíduo de jupati, jornal e papel pós-consumo respectivamente

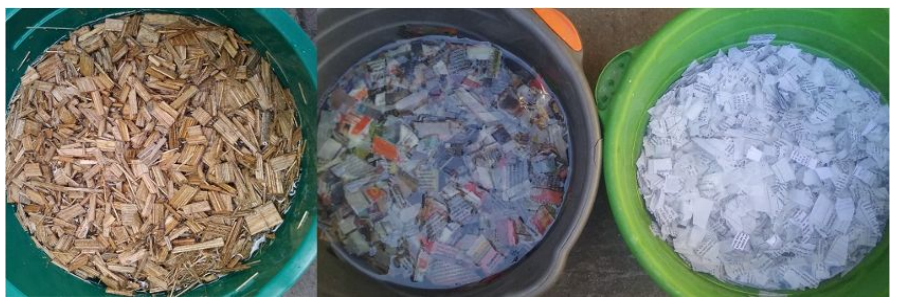

Fonte: AUTORA, 2017

Após 48 horas na água o jupati foi cozido por 4 horas. A partir disso, iniciaram-se os primeiros testes. Foi triturado em liquidificador doméstico o jupati e o jornal, um de cada vez, em porções pequenas de aproximadamente a mesma quantidade, recobrindo a lâmina e com adição de água para que o material pudesse ser triturado sem grande resistência. Depois de batidos, ambos foram postos em uma peneira de plástico para retirar o excesso de água. Em seguida, misturou-se o jupati e jornal triturado no liquidificador novamente e acrescentou-se anilina (para analisar se o material é apto a receber coloração), um pouco de água, de modo que o material se misturasse, e a cola branca.

Figura 3- Cozimento das fibras, trituração, formação da polpa com papel, anilina laranja e cola branca, respectivamente
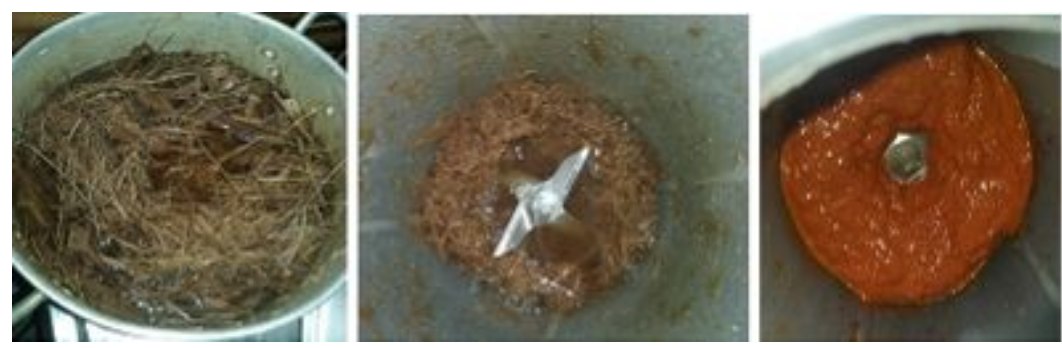

Fonte: AUTORA, 2017 
A polpa formada foi posta na peneira novamente, amassada para eliminar o excesso de água e em seguida depositada em um molde feito de isopor com superfície curva e sem bordas, pressionando para que a amostra se apresentasse de forma homogênea (fig.4, a).

A secagem foi realizada de forma natural em temperatura ambiente, somente pelo período da manhã foi exposta ao sol, levando quatro dias para secar por completo.

Outro teste foi realizado utilizando o jornal sem anilina (fig.4, b). O processo foi o mesmo que o anterior, a diferença é que a polpa formada foi modelada à mão no formato de uma bola e também levou quatro dias para secar por completo.

Foi realizado o teste com o papel sulfite pós-consumo utilizando o mesmo processo com molde de superfície plana também sem bordas (fig.4, c). Por fim, realizou-se o quarto e último teste utilizando o jupati e a cola de madeira (fig.4, d), feita pelo mesmo processo e modelado à mão no formato de um prato. Aqui, foram usados somente o resíduo de jupati e cola de madeira, demorando apenas dois dias para secar, sendo a mais leve das amostras.

Figura 4 - Amostras do primeiro teste
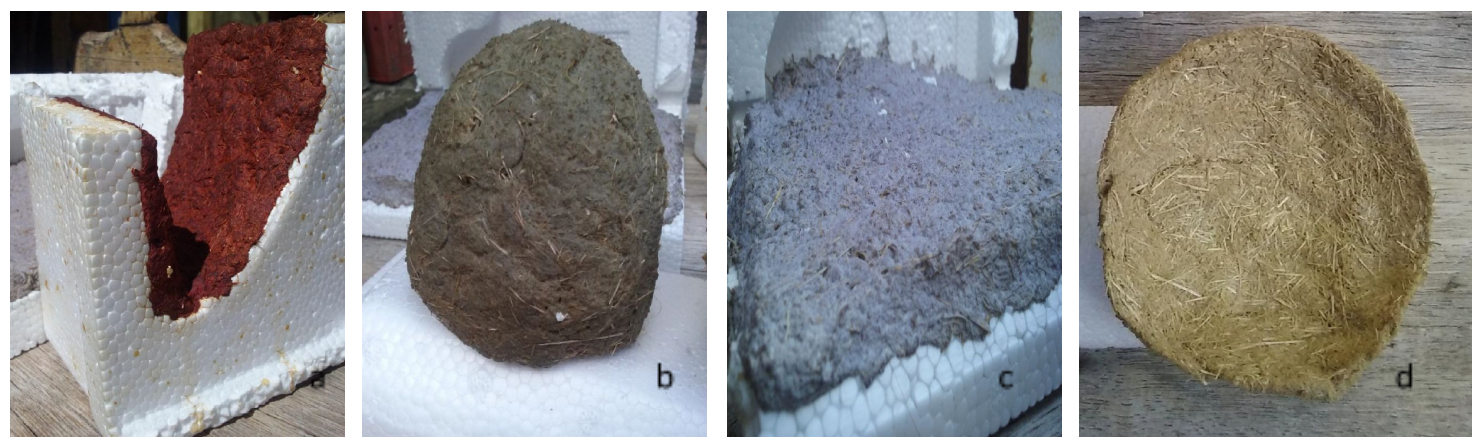

Fonte: AUTORA, 2017

\subsubsection{Análise e discussões}

Os primeiros testes realizados obtiveram resultados satisfatórios. A junção dos papéis com o resíduo foi uma aposta acertada fazendo com que o material se apresentasse leve, resistente e rígido. O resíduo precisou ser submerso por 48 horas e posteriormente cozido por 4 horas para que acontecesse o desfibramento do material, já o papel teve que descansar em água por 24 horas para que suas fibrilas se soltassem, dessa forma melhorando a trituração no liquidificador e a polpa final formada.

Observou-se que a mistura do resíduo de jupati com o jornal (fig.4, a) e do jupati com o papel pós-consumo (fig.4, c) tornaram-se consistentes, entretanto com o jornal a amostra se apresentou mais escurecida. Ambas puderam ser modeladas, porém a utilização de um molde foi mais apropriado já que a polpa apresenta aspecto viscoso. A amostra feita somente com jupati e cola de madeira (fig.4, d) funcionou, porém originou fissuras e soltou resíduos com mais facilidade.

Importante ressaltar que a face do material que estava em contato com o molde se adere bem à superfície e deixou-a mais clara, lisa e uniforme, já a face exposta tornou-se mais escura e rugosa. A utilização de anilina também confirma que o material está apto a receber coloração, criando um efeito único onde o material se apresenta opaco, mas as fibras expostas do jupati brilham. Analisou-se também que o material pode receber qualquer forma (curva, plana, cilíndrica e esférica) o que proporcionará diferentes tipos de produtos decorativos e utilitários.

De modo geral, esse primeiro contato foi satisfatório e importante à pesquisa, todavia, os testes continuaram para quantificar o material, melhorar o acabamento, utilizar moldes mais resistentes e empregar outro tipo de aglomerante visto que as colas utilizadas são nocivas ao meio 
ambiente, principalmente a de madeira.

Figura 5- Todas as amostras realizadas após sua cura

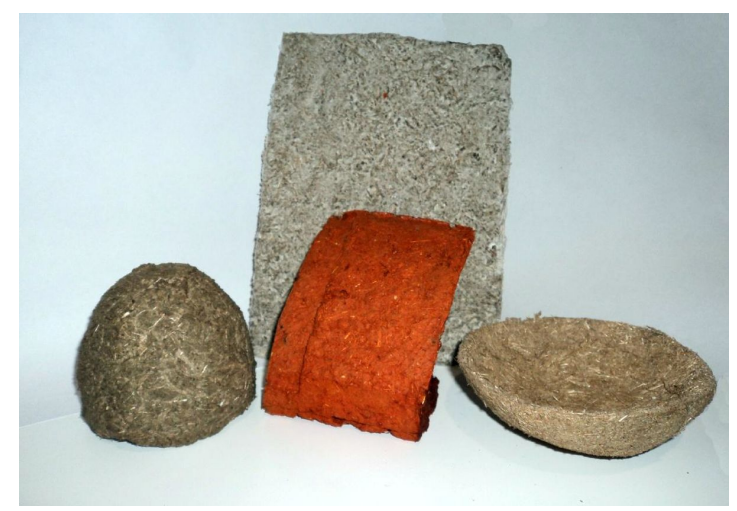

Fonte: AUTORA, 2017

\subsubsection{Testes com amido}

A fim de substituir a cola de madeira e a cola branca, testes utilizando o amido de mandioca foram realizados, por ser um material de fácil acesso que já é usado com essa finalidade em trabalhos manuais. Para fazê-la utilizou-se água e goma (amido de mandioca), aquecidos em fogo médio até se tornar um grude com aspecto de cola de isopor.

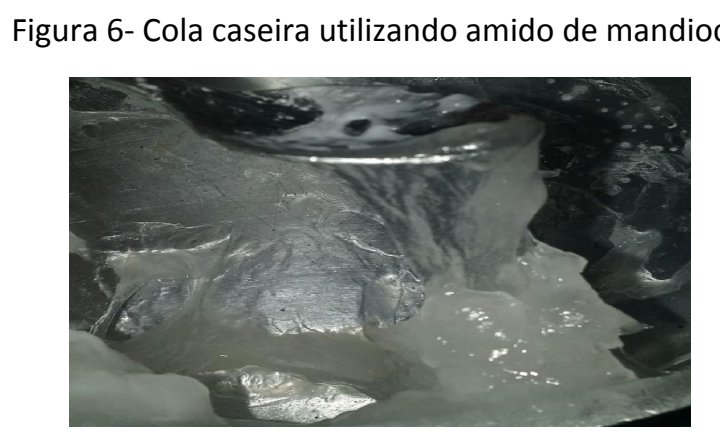

Fonte: AUTORA, 2017

Todo processo anterior foi realizado juntando a ele a cola de amido, em seguida, o material (a polpa formada) foi colocado em vasilhas utilizadas como moldes. A sua secagem foi realizada em temperatura ambiente, apenas durante a manhã as amostras foram expostas ao sol e secaram completamente após quatro dias. Neste teste foram feitas duas amostras.

Algo que chamou bastante atenção foi o acabamento que o amido proporcionou a peça depois de seca, com textura lisa, plastificada e homogênea na face em contato com o molde. A outra face, assim como as amostras anteriores, se apresentou rugosa e escurecida após exposição solar, apesar disso, este teste tornou-se melhor do que o primeiro principalmente devido o acabamento. 
Figura 7- Amostras elaboradas utilizando a cola de amido de mandioca como aglutinante

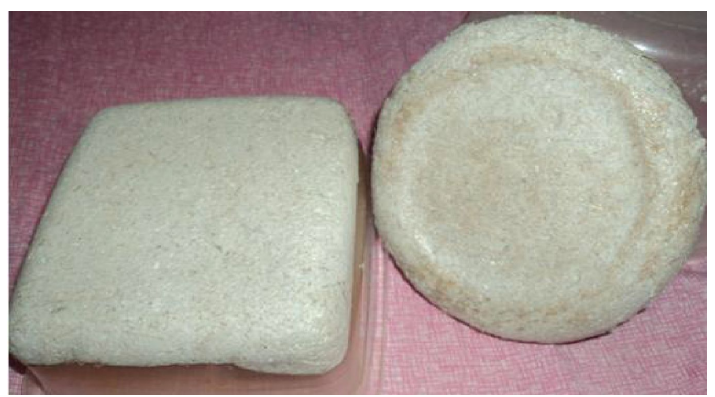

Fonte: AUTORA, 2017

Outro teste foi elaborado para quantificar o material utilizado. Assim sendo, para formar o material o processo foi realizado da mesma maneira dos demais, visto a seguir com as quantidades especificadas:

- No liquidificador, foram triturados $50 \mathrm{~g}$ de jupati aproximadamente (considerando a absorção de água), o equivalente a um copo de $150 \mathrm{ml}$, cobrindo a lâmina com água para melhor trituração;

- Da mesma forma foi feito com o papel, triturando aproximadamente $85 \mathrm{~g}$ (considerando a absorção de água) que também equivale a um copo de $150 \mathrm{ml}$;

- Cada material foi triturado separadamente sendo unidos após a trituração do papel, nesse momento adicionando a cola de amido de mandioca;

- A quantidade de cola foi medida também com o copo de $150 \mathrm{ml}$, adicionando na polpa o equivalente a $3 / 4$ da capacidade total do copo. Após acrescentar a cola, adicionou-se a água ao processo para misturar todo o material no liquidificador;

- $\quad$ Ressalta-se que essa medida é para peças pequenas, quanto maior o produto a quantidade aumenta proporcionalmente, assim como a cola;

- Após a mistura, o material foi despejado em uma peneira para retirar o excesso de água e posto em moldes de superfície lisa, nivelando a superfície exposta com o auxílio de uma espátula;

- $\quad$ As peças foram secas em temperatura ambiente e exposição solar durante a manhã por quatro dias, tempo necessário para a cura do material.

Figura 8- Produção realizada utilizando apenas uma medida

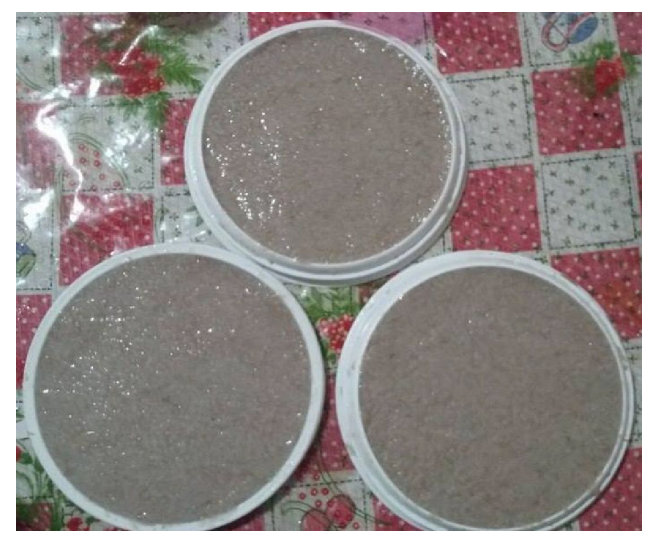

Fonte: AUTORA, 2017 
A partir dos resultados obtidos, analisou-se que a cola caseira proporciona melhor acabamento ao material devido seu aspecto envernizado, mas, caso seja preferível, não isenta o uso da cola branca que obteve bom desempenho. Constatou-se também que o resíduo e o papel são materiais rentáveis onde com apenas uma medida podem ser produzidos diversos objetos, dependendo do seu tamanho e espessura.

Quanto aos moldes, o ideal é que sejam com superfícies lisas (resultados satisfatórios apresentados com a utilização de vasilhas plásticas) prensando o material- utilizando molde macho, positivo, e fêmea, negativo- para que se torne homogêneo e diminua, assim, as imperfeições. Por ser um material totalmente biodegradável, a impermeabilização se faz necessária para inibir o contato com a água e a proliferação de fungos, assim prolongando sua vida útil. Para o desenvolvimento de produtos, a comunidade artesã teve ampla participação no processo de criação do conceito e nas linhas de produtos.

\subsection{Workshop}

Foi realizada uma visita in loco a comunidade do furo Pirarara, ilha de Chaves, pertencente ao município de S. S. Boa Vista, com o objetivo de levar aos artesãos a tecnologia desenvolvida. Por intermédio de um workshop, eles puderam entender que o descarte de sua produção é mais uma possibilidade de renda, desenvolvendo outros produtos ainda com a forte identidade cultural que carregam, feitos a partir da elaboração do compósito.

O Workshop foi promovido no barracão da Comunidade Cristo Rei do furo Pirarara e teve como nome "RE.conhecer" com o intuito de causar surpresa e curiosidade nos participantes para que conhecessem o jupati de uma forma diferente do habitual. Realizado entre os dias 12 a 15 de outubro de 2017 (quatro dias), contou com a presença de nove pessoas, entre artesãos e seus familiares, de diferentes faixas etárias e em sua maioria mulheres. No primeiro dia, foi realizado o convite e inscrição dos interessados e o corte do resíduo de jupati pela manhã e à tarde a abertura do workshop com uma breve explanação sobre a pesquisa, o objetivo daquela atividade na comunidade e o processo de elaboração do compósito.

Depois, foi proposto a eles uma dinâmica para que pudessem contar seu cotidiano e vivências, com o intuito de conhecer a comunidade e a partir desses relatos pensar no conceito e nas linhas de produtos. A atividade proposta foi o "baú de memórias" onde com a ajuda de um dado eles puderam falar de um tema específico -trabalho, lazer, alimentação, família, religiosidade e transporte. Em seguida, foi pedido para que em dupla formassem painéis que simbolizavam através de imagens seus relatos. Os painéis evocaram cores, texturas, linhas e formas abstratas que manifestavam as percepções, memórias e relações que a comunidade vive e está imersa. Com isso foi possível identificar palavras-chaves que traduzem a cotidianidade, a memória e os modos de ser e viver no Marajó de S.S. da Boa Vista. Esse processo serviu de guia para o desenvolvimento do conceito e das linhas de produtos.

Figura 9- Participantes e seus respectivos painéis

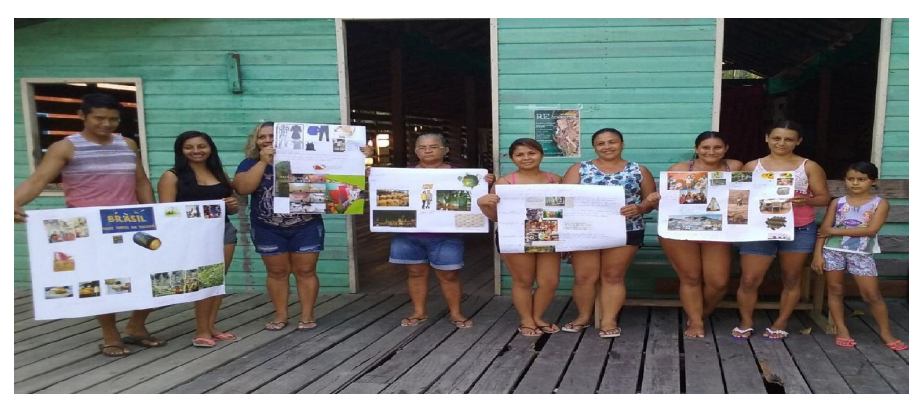

Fonte: AUTORA, 2017 
Com base nessa imersão no cenário, apropriou-se da metodologia trazida por Lucy Niemeyer (2003), em seu livro: Elementos de Semiótica aplicados ao Design, quando trata do desenvolvimento da Voz Visual do produto, para gerar as linhas de produtos. Dessa forma realizou-se uma sessão de brainstorming que sintetizou tudo o que foi vivenciado durante a imersão. Concluído a tempestade de ideias, os termos selecionados foram analisados e se fez sucessivas eliminações até chegar a uma síntese: três ou quatro palavras (NIEMEYER, 2003). As palavras selecionadas que sintetizaram os valores a serem aplicados no conceito da linha de produtos foram: conexão, acolhimento e movimento (linhas) tudo ditado pelo tempo (conceito geral).

Em suas falas era forte o afeto e acolhimento que sentiam com seus amigos, vizinhos, sua casa, a natureza e quem mais visitasse a comunidade. Também foi marcante o respeito e orgulho pelo trabalho, aprendido com parentes ou pessoas mais próximas, e em alguns relatos o sentimento de saudade aflora quando por algum motivo o interrompem. Perceptível que eles não se limitam apenas a uma tarefa, quando não trabalham com o que gostam fazem outras atividades, por esse motivo estão sempre em movimento. Esse movimento também está em conexão ao fluxo que os rodeiam, ao ir e vir de cascos, rabudos e rabetas (espécies de barcos de madeira, o primeiro movido a remo e os demais a motor) e as maresias que atravessam. Observou-se também a conexão que possuem com o lugar e aos sinais que a natureza determina para fazer algo (como o melhor período para apanhar o açaí, o jupati, atravessar o rio principal para ir a cidade de Boa Vista ou em comunidades vizinhas). Não deixando de mencionar a união dos vizinhos em um propósito comum e a integração das próprias casas que apresentam ambientes separados, mas interligados por pontes, tornando-se assim uma unidade, um ambiente de partilha onde dividem momentos diversos. Todos esses fatores são gerados pelo tempo não apenas cronológico, mas o tempo de convivência ou o que a natureza determina.

No segundo dia de workshop foram explicadas ao grupo as conclusões chegadas a partir da análise dos painéis elaborados e apresentada as linhas de produtos pensadas para a coleção. Com a concordância dos fatos, iniciou-se a etapa de geração de alternativas. Surgiram ideias interessantes e que retratavam o cotidiano dos participantes, visto principalmente pelo uso das cores em suas composições. Apesar de alguns desenhos não serem passíveis a produção no momento algumas ideias permaneceram e serão vistas mais adiante.

No terceiro e quarto dia de workshop foi realizada a elaboração do compósito. Cada participante recebeu um passo a passo contendo: os materiais utilizados, as quantidades, o modo de preparo e a receita da cola de amido de mandioca. Cada participante fez o seu material, com a supervisão da autora caso houvessem dúvidas, dessa forma engajando-os a desenvolverem o compósito e a fixar as etapas. Em cada etapa explicava-se o porquê de proceder daquela maneira e das escolhas dos materiais utilizados para formar o compósito, isso provocou nos participantes a compreensão na prática de conhecimentos científicos.

Figura 10- Participantes elaborando o compósito

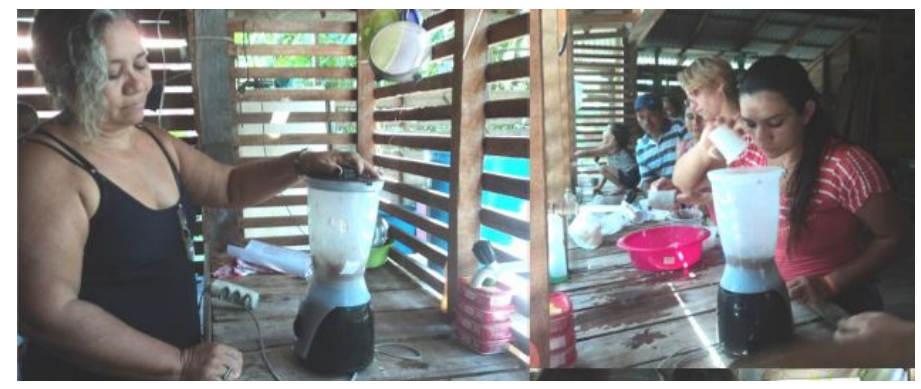

Fonte: AMANDA CAREN, 2017 
Nesse momento foi solicitado a eles que seguissem alguns esboços que poderiam ser produzidos com os moldes levados e em seguida deixou-os livres para elaborar o que quisessem. Por falta de moldes adequados aos desenhos gerados algumas peças foram modeladas à mão. Interessante que, apesar de seguir o passo a passo, cada participante teve seu jeito de elaborar o material e com algumas observações conduziram a situação, como, por exemplo, a água do material que poderia ser retirada usando um pano ou um papel toalha e assim secar mais rápido, ou a possibilidade de deixar a polpa pronta e armazenada ainda molhada para modelar produtos que levem mais tempo de produção.

Figura 11- Compósito em moldes, modelagem à mão e secagem com pano, respectivamente

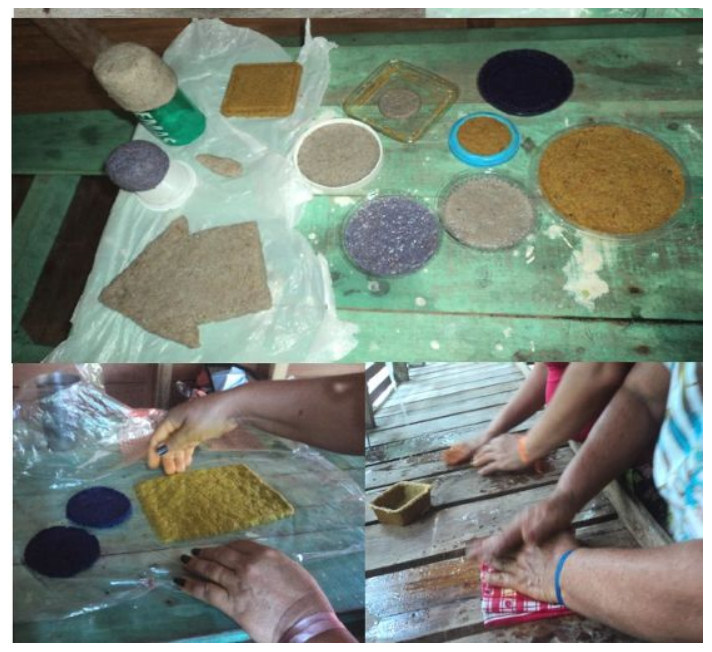

Fonte: AUTORA, 2017

Após a finalização das atividades encerrou-se o workshop com os relatos da experiência, onde cada participante pode avaliar o trabalho realizado, propor melhorias e outras formas de aplicação do material.

\subsubsection{Resultados}

De modo geral, o workshop foi satisfatório e cumpriu com o seu objetivo, levar a tecnologia social desenvolvida para a comunidade. Os participantes ficaram surpresos pela forma como o resíduo do jupati foi exposto, pois acreditavam que seria uma atividade para reutilizar o resíduo como adubo. Eles apresentaram entusiasmo com a iniciativa e pediram para que essa parceria continue e que origine novos conhecimentos. Também fizeram uma autocrítica, para maior participação da comunidade- visto que algumas pessoas participaram apenas do primeiro dia de workshop-, pois, dessa forma, incentiva-se um melhor aprendizado, troca de conhecimentos e melhorias no processo.

Foi exposta por eles a possibilidade de elaborar o compósito com fibras desfiadas para que o material não apresente pontas (devido o corte do material) na sua superfície, tornando-o mais atrativo e assim pensaram em fazer novas experimentações. Outra ideia, que incentivou os mais jovens a continuar elaborando o compósito, foi aplicar o material em acessórios de moda, desse modo enxergaram uma nova fonte de renda na utilização do descarte artesanal.

Quanto aos produtos elaborados infelizmente devido o tempo não foi possível retornar para realizar o acabamento das peças, todavia o objetivo, mostrar a eles como elaborar o biocompósito, foi cumprido. Algumas ideias esboçadas no workshop foram desenvolvidas com o cuidado de encaixá-las nas linhas geradas. O primeiro, linha Conexão (fig 12, a), usou a palavra "relação" para desenvolver o conjunto de descanso de panela, elaborado a partir da junção de dois esboços. O segundo, linha Acolhimento (figura 12, b), buscou a partir do esboço das casas 
ribeirinhas a ideia de guardar o lar, desenvolveu-se assim um porta-chaves.

Figura 12- Esboços de inspiração e produto da linha Conexão e acolhimento, respectivamente

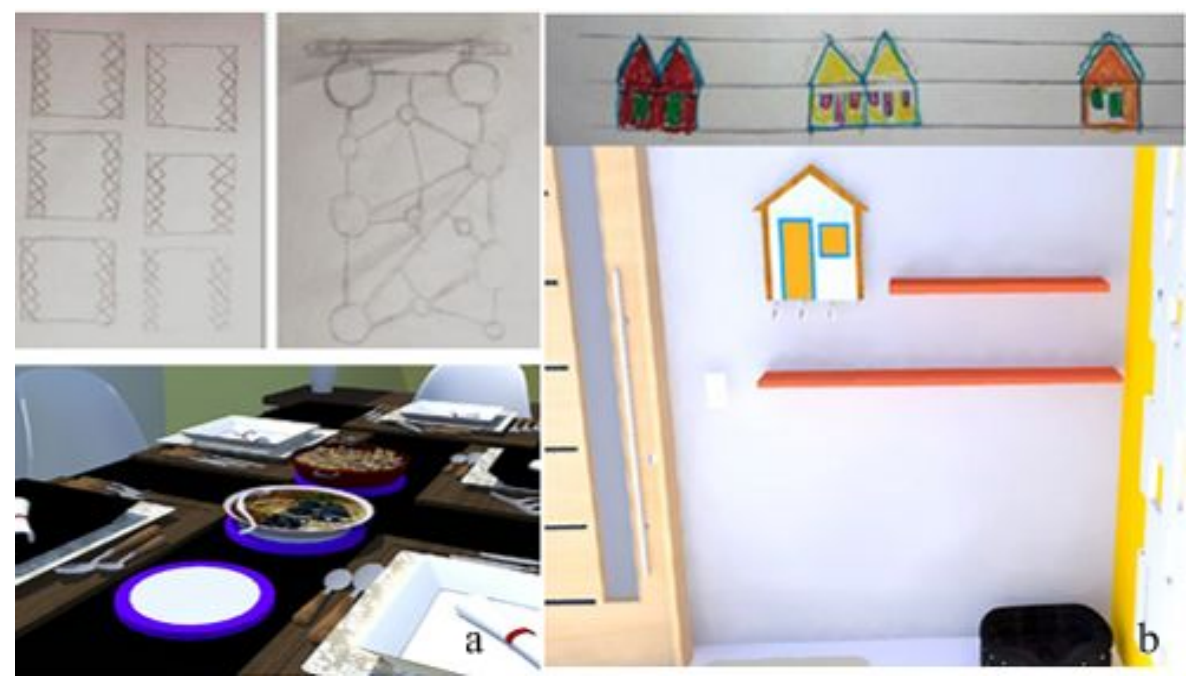

Fonte: AUTORA, 2017

O terceiro, linha Movimento, representa o cotidiano ditado pelo tempo traduzido em um relógio de parede onde os ponteiros são fibras de jupati tingidas e sua base o compósito, como mostra a figura a seguir, junto aos produtos físicos.

Figura 13- Esboço de inspiração, produto da linha Movimento e produtos físicos das três linhas

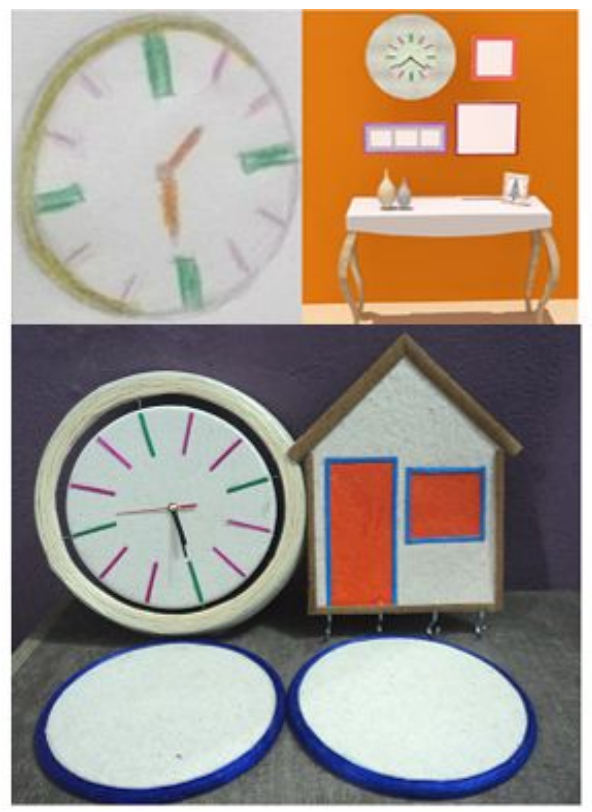

Fonte: AUTORA, 2017

\section{Considerações finais}

Após toda pesquisa teórica e prática, constata-se que é possível elaborar um compósito utilizando o resíduo do jupati e inseri-lo em diversos produtos artesanais, o que proporcionou um novo destino a matéria-prima descartada para benefício da própria comunidade. 0 compósito obteve resultados satisfatórios, todavia precisa ser aperfeiçoado em sua aplicação, no que tange a impermeabilização, pois, além de ser passível a proliferação de fungos, seus elementos são 
formados por celulose (presente no papel), fibras ligno-celulósicas (no resíduo do jupati) e amido (da cola de mandioca), todos provenientes de fontes renováveis e naturais, sendo assim de fácil biodegradação principalmente em contato com a água (esse fator é ao mesmo tempo negativo e positivo, pois quando uma peça não sair como esperado esta pode ser refeita com facilidade). Por essas características, o material também é denominado como um biocompósito. Quanto ao processo, apresentou-se satisfatório, houveram como já mencionado, novas ideias para elaborar o material e os produtos por parte dos participantes, o que ratifica a aceitação e interação com a tecnologia desenvolvida, tornando claro que a criação coletiva traz melhorias nas técnicas e abertura a novas ideias de processo e produção. Por fim, os resultados obtidos tornaram-se fonte de conhecimento sobre sustentabilidade, processos produtivos e valorização de identidade cultural, temáticas que motivam a continuação da pesquisa. Espera-se que este trabalho seja referência aos demais interessados e mais um documento para engrandecer a produção científica amazônica.

\section{Referências}

ASHBY, M. F.; JOHNSON, K. Materiais e design: arte e ciência da seleção de materiais no design de produtos. Rio de Janeiro: Elsevier, 2011.

BORGES, Adélia. Design + Artesanato: o caminho brasileiro. São Paulo: Editora Terceiro Nome, 2011.

COSTA, Manoela Maria Costa da; SIMÕES, Vanessa Cristina Ferreira. Design de superfícies e tradição artesanal: produtos inspirados no artesanato em fibra de jupatí de São Sebastião da Boa Vista- Marajó. Belém: UEPA 2011.

FERRI, Mário Guimarães. Botânica: morfologia externa das plantas. São Paulo: Nobel, 1983.

JARDIM, Ninon Rose. Mulheres entre enfeites\&caminhos: cartografia de memórias em saberes e estéticas do cotidiano no marajó das florestas (s.s. da boa vista - pa) / Ninon Rose Tavares Jardim. Belém, PA: - 2013.

KRUCKEN, Lia, Design e território: valorização de identidades e produtos locais. São Paulo: Studio Nobel, 2009.

LIMA, Marco Antonio Magalhães. Introdução aos Materiais e Processos para Designers. Rio de Janeiro: Editora Ciência Moderna Ltda, 2006.

NIEMEYER, Lucy. Elementos da semiótica aplicados ao design. Rio de Janeiro: 2AB, 2003.

MANZINI, Ezio; VEZZOLI, Carlos. O Desenvolvimento de Produtos Sustentáveis. Tradução Astrid de Carvalho. - 1ed. 4. reimp. São Paulo: Editora da Universidade de São Paulo, 2016.

OLIVEIRA, J. et al. JUPATÍ (RAPHIA TAEDIGERA MART.): A SUA UTILIZAÇÃO POR COMUNIDADES

RIBEIRINHAS DO ESTADO DO PARÁ. Disponível

<http://www.alice.cnptia.embrapa.br/handle/doc/575004> Acesso em: 06 mar. 2017.

PAMPLONA, Vitória Martins Soares. O uso de papel reciclado e fibras vegetais na produção de produtos para o Design de Superfície. Belém: UEPA, 2012.

SANTOS, Celênia Pereira et al. Papel: como se fabrica. Química Nova na Escola. Disponível em: <http://qnesc.sbq.org.br/online/qnesc14/v14a01.pdf> Acesso em 01 out. 2017.

SANTOS, Nubia Suely Silva. Análise experimental e teórica do comportamento mecânico sob carregamentos quase-estáticos de compósitos reforçados com fibras vegetais / Nubia Suely Silva Santos. Campinas, SP: [s.n.], 2010. 